must at some time make a decision when to stop reviewing the literature. Here, with coverage up to 1978 , they have therefore missed some of the more important epidemiological studies on dioxin exposure in industry and silviculture.

Recently published studies of people exposed to dioxin in industry offer apparently conflicting evidence. The first investigation, of workers exposed to the chemical at the Monsanto company in West Virginia in 1949, clears dioxin - for the moment - of causing any increase in the mortality rate in the men; deaths in this group were in fact lower than would be expected. The second study, of workers exposed to dioxin in an accident in West Germany, suggests that the chemical could be the cause of an increase in gastrointestinal cancer. A third survey, of workers employed in the forestry industry in Sweden, also claims that exposure to dioxin-contaminated $2,4,5-\mathrm{T}$ could have increased the incidence of deaths from cancer. The authors of this study claim that silviculture workers exposed to $2,4,5-\mathrm{T}$ have a six-fold higher incidence of soft tissue sarcomas (see Nature 283, 613;
1980).

In their concluding chapters Bovey and Young detail the processes involved in registering new chemicals and list many suitable alternatives to phenoxy herbicides - although, as stated earlier, their view is that the phenoxy herbicides are not a great hazard. The economic consequences of dispensing with them is assessed as follows: an increase in farm production costs of $\$ 290$ million, and the requirement of an additional 20 million hours of family labour to clear the foliage the herbicides keep down so effectively. However, it is not clear whether these figures are based on a situation where alternative herbicides are employed or one where no herbicides are used at all.

On phenoxy herbicide use for military purposes, the authors are quite explicit. Their use "in an armed conflict [in Vietnam] has jeopardised their continued use in world agriculture". The authors are not convinced that the use of $2,4,5-\mathrm{T}$ in Vietnam - recognized to have had a dioxin content of 0.05-47 ppm - has caused birth defects among the general population, as has been claimed by Vietnamese scientists and doctors. However, Bovey and Young note that many scientists still hold different views on this subject and that more evidence is required before the issue can be resolved. The authors also claim that the incineration of the unused herbicide stocks from Vietnam means that "it is no longer an issue"'. Using herbicide destined for Vietnam may not be an issue - but the legacy of its use in that country is still very much in the public eye, following claims by former US veterans that the herbicide has damaged their health.

It remains to be seen whether reviews currently being conducted by government bodies in the UK and USA will come to the conclusion that the use of present formulations of 2,4,5-T also poses a health risk. Whatever the verdict, the authors make the plea that the suspension of 2,4,5-T and other products based on trichlorophenol "should not jeopardise other phenoxy herbicides". By all accounts the others are not in jeopardy.

Alastair Hay is a Lecturer in the Department of Chemical Pathology at the University of Leeds.

\section{Odours and vertebrate ecology}

\author{
Vincent B. Wigglesworth \\ The Ecology of Vertebrate Olfaction. By \\ D. Michael Stoddart. Pp. 234. (Chapman \\ and Hall: 1980.) £15, \$29.95.
}

THE purpose of this book was to put together an inclusive account of all the ways in which the lives of other vertebrates are guided by the richly scented world that is beyond our ken. Comparative anatomy of the olfactory system suggests that we differ from our more osmatic relatives in quantity rather than in quality; in the restricted area of our olfactory epithelium in comparison with the capacious chambers of other animals. As far as sensitivity is concerned, it sounds quite impressive to point out that the human female at the height of her sexual cycle can perceive the odour of synthetic musk at a concentration of 1 in 1,000 million; but this achievement fades beside the claim that the eel can detect ß-phenylethyl alcohol at concentrations as low as $3 \times 10^{-18} \mathrm{M}$, representing the dilution of $1 \mathrm{ml}$ of the alcohol in a volume of water equal to 58 times that of Lake Constance (Bodensee, the $60 \mathrm{~km}$ lake on the Swiss-German border) - which will provide the eel with about three molecules in its olfactory sac at one time.

A survey of the chemistry of vertebrate scents reads like a catalogue of organic chemicals, but on closer analysis it seems that virtually all are refined waste products of metabolism and few or none are synthesized de novo. Moreover, although the glands from which they are liberated can be concentrated in many different parts of the body, they seem always to be modified, often scarcely modified, sebaceous glands, the secretory products of which are influenced by diet.

The book provides a detailed account of the multifarious roles of olfaction the detection of food by herbivores and carnivores; the attraction of a mate and the advertisement of sexual state; the induction of oestrus and ovulation; the conduct of courtship and mating; the discrimination of families, populations and races (thus aiding sexual isolation between species); the maintenance of social hierarchy and territoriality; the detection of predators; the transmission of warning signals or active defence; and homing and navigation.

Olfaction is greatly involved in reproduction - in sexual attraction or the excitation of females by the rutting male, which may induce simultaneous oestrus in a wide group of females. In that most human of animals, the tortoise, the female in the early stages of courtship rubs her forearms against her chin glands and then proffers her perfumed arms to passing males. Even pregnancy may be upset by olfaction: in female mice the presence of a strange male or just his urine may prevent implantation of existing blastocysts in the female and may even terminate pregnancy more than half-way through gestation. Also, after birth, odour plays an essential role in forging the bond between mother and young.
Olfaction can be important in the isolation of species: among mice the odour preference by the female seems to accord with sound genetic policy in that she prefers an unrelated male of the same stock, avoiding males of remote strains and rejecting siblings.

The author naturally devotes much attention to the marking of territory - a world of sense and a complex language which it is difficult for us to understand. It would seem, in general, that marking does not serve to keep intruders out but acts rather as a bond within the colony which boosts self-confidence and thus the ability to get the better of unwelcome intruders.

In a final chapter the author outlines some of the ways in which an understanding of the role of olfaction in the ecology of vertebrates may be utilized in improving husbandry or combating vertebrate pests. He does not claim too much. But in his eyes the grass looks greener on the other side of the fence; he gives a brief account of the use of pheromones in insect control which might fairly be described as optimistic.

This book is packed with information, well organized and fully documented with references. The author favours theories based on observational or experimental science. $\mathrm{He}$ is sceptical of conclusions based on anecdotes and pays only minimal attention to Freudian fantasies. $\mathrm{He}$ is therefore a good guide for the serious student of ecology.

Sir Vincent B. Wigglesworth is Emeritus Professor of Biology in the University of Cambridge. 